\title{
AUTOMATION AND INFORMATIONAL SUPPORT OF BUDGETARY INSTITUTION FINANCING Processes
}

\author{
ALASHKEVICH, M.; BOBRYAKOV, A.; \\ KLIMENKO, A. \& STEFANTSOV, A.
}

Abstract: The effectiveness of the budgetary sectors economy is largely determined by the applicable principles and mechanisms of subordinated institution financing. Introduction of new funding principles aimed at improving the quality of public services and the optimization of budget expenditures requires the development and establishment of appropriate methods and means of automation, information, and decision support. This article describes the architectural and structural solutions, approaches and principles of an integrated set of specialized information and analytical systems for planning and funding systems of the educational institutions network, subordinated under the Ministry of Education and Science of the Russian Federation.

Key words: budget institutions, financing, informational support, decision support, information-analytical systems
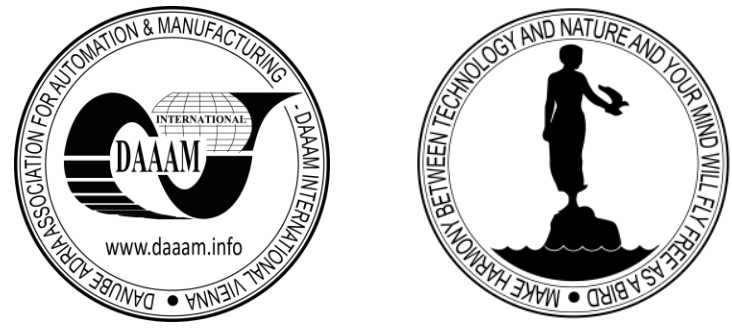

Authors' data: Director of Financial Department Alashkevich, M[ikhail]*; D.Sc. (Eng.) Head of Department Bobryakov, A[lexander]**; Univ.Prof. D.Sc. (Eng.) Klimenko, $\quad \mathrm{A}[$ lexander]**; $\quad$ Ph.D. Stefantsov, $\mathrm{A}[$ lexey]**. *Ministry of Education and Science of the Russian Federation, Tverskaya 11, Moscow, 125993, Russia; **National Research University "Moscow Power Engineering Institute", Krasnokazarmennaya 14, Moscow, 111250, Russia, alashkevich-my@mon.gov.ru, BobriakovAV@mpei.ru, KlimenkoAV@mpei.ru, StefantsovAG@mpei.ru.

This Publication has to be referred as: Alashkevich, M[ikhail]; Bobryakov, A[lexander]; Klimenko, A[lexander] \& Stefantsov, A[lexey] (2015). Automation and Informational Support of Budgetary Institution Financing Processes, Chapter 27 in DAAAM International Scientific Book 2015, pp.319-328, B. Katalinic (Ed.), Published by DAAAM International, ISBN 978-3-902734-05-1, ISSN 1726-9687, Vienna, Austria

DOI: $10.2507 /$ daaam.scibook.2015.27 
Alashkevich, M.; Bobryakov, A.; Klimenko, A. \& Stefantsov, A.: Automation and I...

\section{Introduction}

The introduction of new financing methodology for public institutions that is aimed at improving the quality of public services and increasing budget spending efficiency is a key element for the ongoing reform of the Russian public sector. The methodology is based on an integration of the methods of formulating government assignments (GA) for subordinate institutions, and on the calculation of financial support for its implementation. This calculation is completed using target costs and budgetary financing allocations in the form of various subsidies (Borovskaya et al., 2012). The methodology significantly expands the financial independence of public institutions, which allows for the effective utilization of available financial resources in order to improve the quality of public services offered.

The effective introduction of new funding principles requires the establishment and wide practical application of a developed means of informational support, the automation of basic financial support calculations, and current funding and monitoring of the financial and economic activity of subordinate institutions. It is especially important to solve informational support issues and automate the funding processes of large-scale budgetary institutions, one of which is the Ministry of Education and Science of the Russian Federation. The Ministry of Education and Science of the Russian Federation encounters difficulties solving the mentioned issues because of the following circumstances:

- The instability of the legal and methodological basis for calculating the financial support of a government assignment (GA FS);

- A large range of public services rendered, including not only a wide range of educational services provided by each subordinate institution at various levels of education and fields of study, but also a variety of non-essential services offered by a more limited number of institutions;

- A large number of subordinate institutions with significantly different characteristics and differences in their financial and economic activities (volumes of services rendered, geographical location, type, and some individual institutional characteristics);

- The contribution to public services provided by non-public educational institutions not subordinate to the Ministry of Education and Science of the Russian Federation;

- The partial automation of funding processes at the level of the Ministry of Education and Science of the Russian Federation that was carried out at different times, by different software companies, and using different technologies, applied technical platforms, and software.

An effective solution to the particular problems facing industry funding, taking the mentioned factors into account, is not realistic without the development and introduction of comprehensive integrative solutions for the automation and informational support of the processes in question. 


\section{Problems of funding educational institutions and automation tools used}

Organizing the effective funding of educational institutions requires that a number of interrelated strategic and tactical challenges be addressed (Fig 1), namely:

- The long-range strategic task of preparing and monitoring the budgetary allocations for the next financial year and planning period, including:

- Forecast of the industry and identifying key targets;

- Setting of calculation parameters of the financial support of a government assignment (basic standard cost, system of correction coefficients);

- Conducting scenario calculations of the financial support of a government assignment for the forecast periods;

- Selection of the optimal scenario and the formation of proposals for the budgetary allocations;

- Clarifying the budgetary allocations for the next financial year, including:

- Clarification of the main targets for the next financial year and planning period subject to the provisions of the law on the Federal budget;

- Calculation of the financial support of a government assignment prescribed at the previous stage of the model;

- Analysis of the results, correction of the system of coefficients taking into account the approved budget indicators, conducting scenario calculations (if necessary);

- Selection of the optimal scenario and the formation of proposals for the budgetary allocations;

- Tactical tasks for the current funding of the subordinate institution, including:

- Accounting for and managing the current amounts of budgetary allocations for each educational institution (EI);

- Monitoring the financial and economic activities (FEA) of subordinate educational institutions;

- Strategic tasks for optimizing the structure and size of standard cost components and system of correction coefficients, including:

- Implementing procedures for processing statistical and analytical information on the funding and effectiveness of the financial and economic activities of the subordinate educational institution and preparing proposals for optimizing the structure and size of standard cost components and system of correction coefficients;

- Calculating scenario variants for using modified structure and size of standard cost components and system of correction coefficients in the ministry.

Historically, automation and information support for solving these problems have been provided by specialized information systems (IS) developed at different times and operating on various hardware and software platforms. Moreover, each of them was focused on resolving one (or more) particular tasks. The main drawback of existing automation tools is the absence of system-wide approach, namely:

- Topically related problems were solved using different, often poorly interconnected information systems; 
Alashkevich, M.; Bobryakov, A.; Klimenko, A. \& Stefantsov, A.: Automation and I...

- System directories and dictionaries were maintained in a decentralized manner and in separate information systems, which resulted in the ambiguity of stored and processed information;

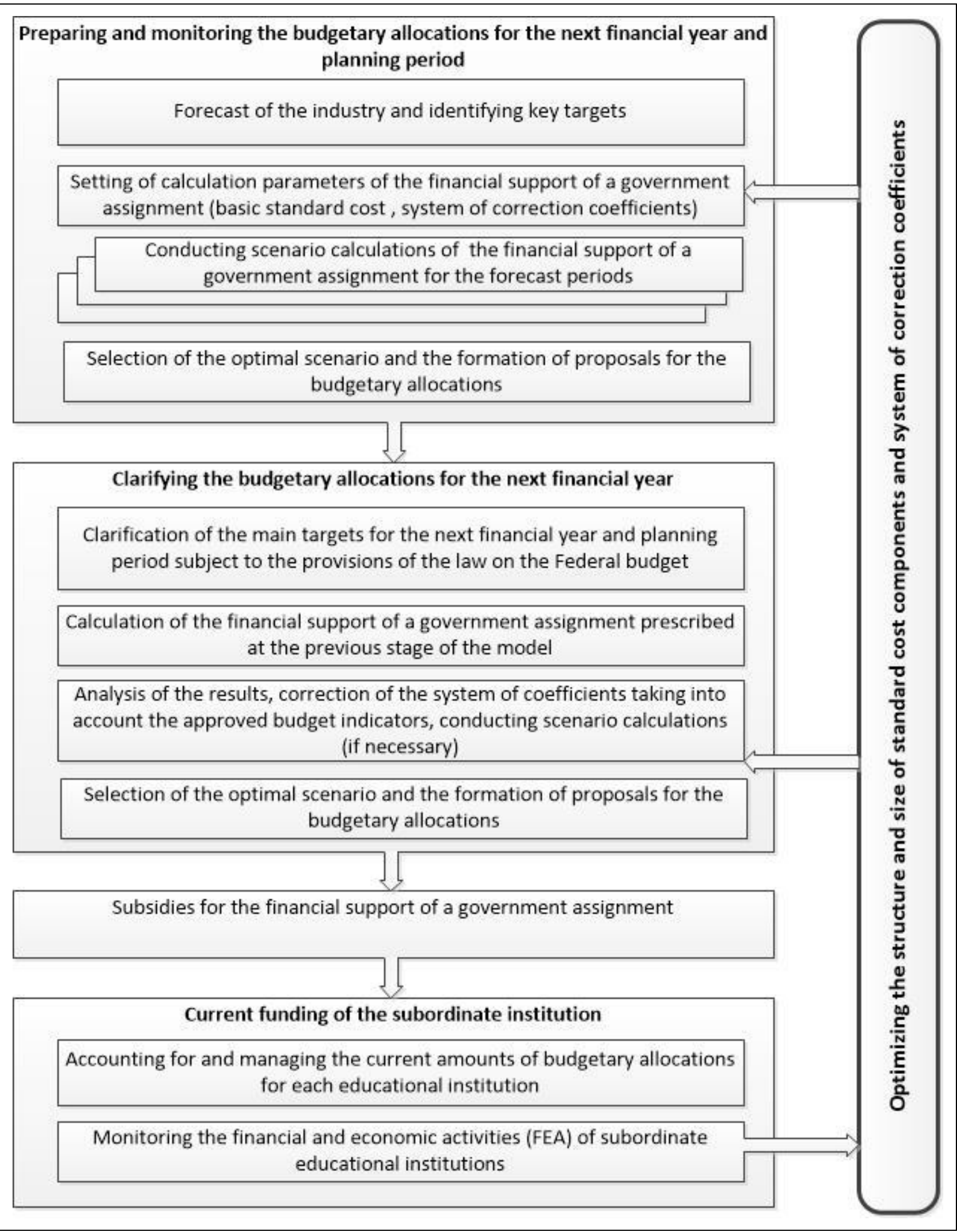

Fig. 1. The main stages of financing of educational institutions 
- Systems usually had no tools for adapting to changes in conditions and problemsolving algorithms;

- Decentralization of tools used to generate statistical and analytical reporting did not enable the efficient and comprehensive solution of problems for decision support at the ministry level.

All this required significant operational expenditures to ensure the interaction of information systems, the consistency and integrity of information, and follow-up and modification of systems in the case of changing requirements for automated processes, as well as to solve decision support problems.

\section{Architectural and structural solutions for building an integrated package of specialized information and analytical systems for funding educational institutions}

Currently, in order to solve the problems of funding educational institutions, the Russian Ministry of Education and Science has developed and implemented an integrated package of information and analytical systems the overall architecture of which is shown in Fig. 2.

This architecture includes the following:

- An Automated Corporate Finance Management System (ACFMS), which functions as a corporate data repository and provides for the collection, aggregation and processing of information from the information systems included in the integrated package (ETL), preparation of analytical reporting (OLAP), implementation of procedures for forecasting analysis and decision support (Inmon \& Linstedt, 2014). The primary users of the system are bus.gov.ru;

- "Budget", an Automated Information System (AIS), which provides for the preparation of government assignments for educational institutions, calculation of financial support for a government assignment (Shilovskaya et al., 2013) and preparation and management of agreements on the provision of subsidies for performing government assignments. The data for AIS is provided primarily by the information system for collection and processing of planning and reporting information (IS CP PRI) and by the departments of the Ministry of Education and Science responsible for funding in specific areas. The results of calculation of financial support for government assignments are fed into the information system for accounting and management of budgetary allocations (IS AM BA) and the information systems of the Ministry of Finance of the Russian Federation;

- An information system for accounting and management of budgetary allocations (IS AM BA), which provides for the management and standardization of system directories and registers (MDM) used by all information systems in the integrated package, support for preparation of agreements on the provision of subsidies for government assignments, interaction with the information systems of the Accounting Department (IS AD) and the official website of the Russian Federation for posting information on 
Alashkevich, M.; Bobryakov, A.; Klimenko, A. \& Stefantsov, A.: Automation and I... state (municipal) institutions, bus.gov.ru (SMI website), in terms of providing for the processes of current funding;

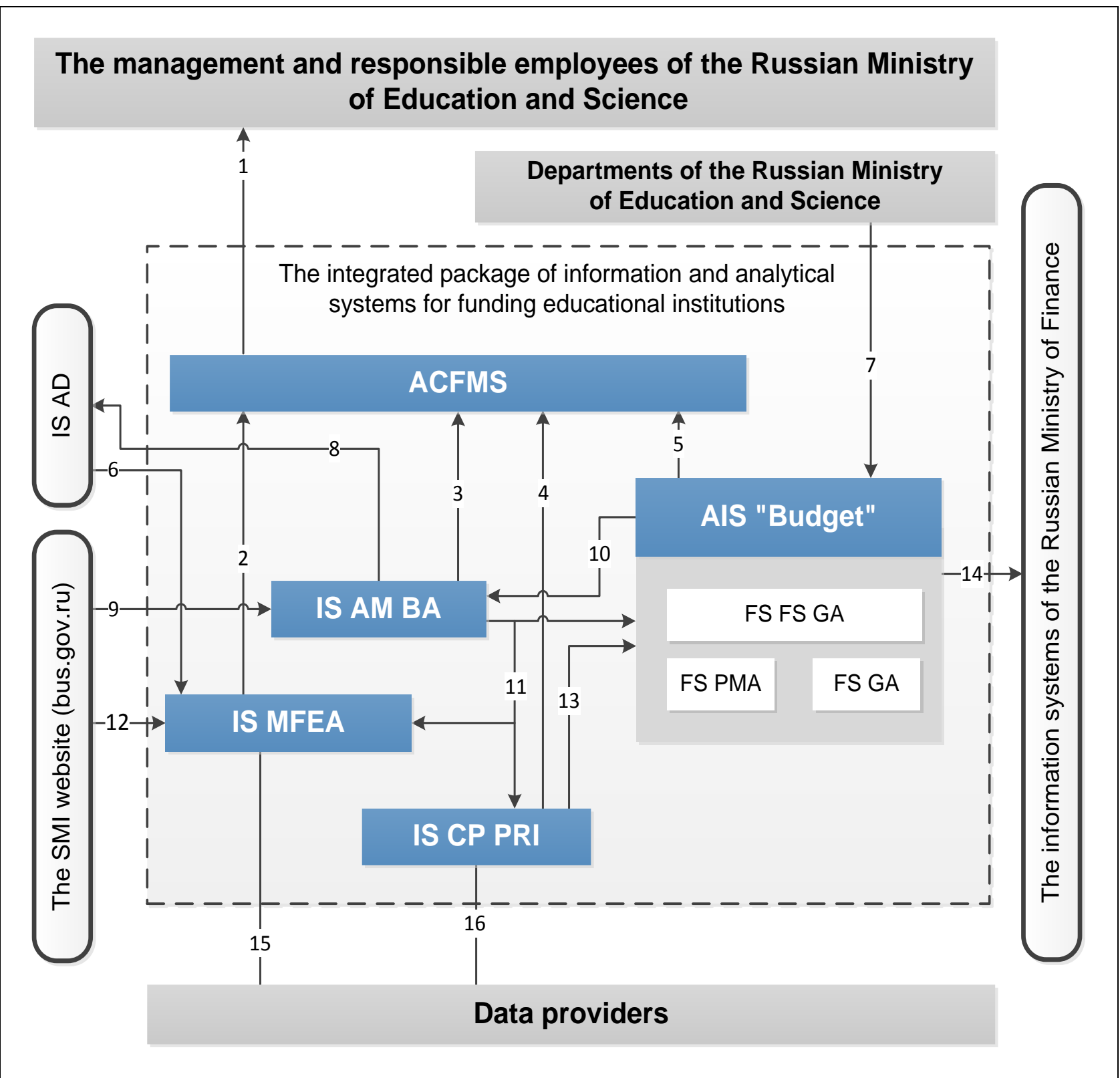

Fig. 2. The architecture of the integrated package of information and analytical systems for funding educational institutions

- An information system for monitoring financial and economic activities (IS MFEA), which provides for automation and information support for the preparation and management of plans for the financial and economic activities of educational institutions (PFEA) (Klimenko et al., 2013). The implementation of PFEAs is monitored using information fed from the information systems of the Accounting Department and the SMI website (bus.gov.ru);

- An information system for collecting and processing planning and reporting information (IS CP PRI), which provides for the collection, verification and initial processing of structured and unstructured information necessary for calculating 
financial support for a government assignment and solving the tactical problems of institutional management. The implementation of verification procedures makes use of various methods of statistical and analytical data processing. Data analysis operations are performed on pre-determined clusters of educational institutions with similar values of quantitative and qualitative characteristics. Clustering procedures use original methods and algorithms based on (Sato-Ilic, 2014). The primary data providers for the IS include educational institutions that are subordinate to the Ministry of Education and Science, as well as non-state educational institutions and educational institutions that are not subordinate to the Ministry of Education and Science. In addition, the system processes information from third-party sources, such as the structural units of the Ministry of Education and Science and federal executive authorities which provide information on specific requests.

The arrows in the figure indicate the main data flows.

1 - Analytical reports, the results of forecast analysis and decision support;

2 - Information on the financial and economic activities of educational institutions;

3 - Current information on budget allocations;

4 - Topical planning and reporting information on the activities of educational institutions;

5 - Information on government assignments for educational institutions, results of calculating financial support for government assignments, information on agreements for the provision of subsidies;

6 - PFEA reports included in the financial statements of institutions;

7 - Information received from the departments of the Russian Ministry of Education and Science and used for calculating financial support for government assignments;

8 - Information necessary for implementing operations on the current funding of educational institutions;

9 - Information on government assignments for educational institutions posted on the SMI website (bus.gov.ru);

10 - Results of calculations of financial support for government assignments needed to prepare agreements for the provision of subsidies;

11 - System directories and dictionaries;

12 - PFEA information posted on the SMI website (bus.gov.ru);

13 - Processed structured and unstructured information used for calculating the financial support of government assignments and decision support for funding of educational institutions;

14 - Structured information on the results of calculating financial support for government assignments;

15 - PFEA information received from data providers;

16 - Structured and unstructured information used for calculating financial support for government assignments and decision support for funding of educational institutions. 
Alashkevich, M.; Bobryakov, A.; Klimenko, A. \& Stefantsov, A.: Automation and I...

The integrated package was built using the following main principles and approaches:

- The integrated package operates as a distributed information system that provides its users with access via the local networks of individual structural units of the Russian Ministry of Education and Science, as well as via the Internet;

- The functioning of the integrated package is implemented within a regulatory and procedural framework that allows different variants of implementing funding processes for various planning periods. The processes for different periods need not be aligned in terms of their composition, types and data structure;

- The key requirements for the main components are the flexibility of the algorithms (models) used for calculations and their performance speed, flexibility of output document forms, and the ability to integrate with external information systems;

- The operation of the integrated package is based on a client-server architecture model implemented using industrial platforms for software development and database management.

The most unstable elements of the integrated package, such as the module for calculating financial support for government assignments, are implemented on the basis of universal data storage using customizable calculation models (Davies et al., 2014).

The customizable model for calculating financial support for government assignments is defined by such elements as the input data, calculation parameters, and operations (calculations) system.

The input data for calculations includes two consolidated blocks:

- The input data block for calculating the next year, which includes the quantitative indicators of the government assignment in the next year with details on characteristics that make it possible to apply a parameter calculation system (for example, a group by the year of admission, forms of training, specialties and training areas, etc.);

- An input data block for model verification, which includes the quantitative indicators in the reporting year (and/or the current year, previous years, previous implementation of the model) and the financial support of a government assignment in the reporting year (and/or the current year, previous years, previous implementation of the model).

Uncontrolled (specified by the federal regulatory framework) parameters for calculation include the regional factors for individual cost components, institution status and standard costs for individual specialties and training areas.

Controlled parameters for calculation include the base standard costs; factors for the base standard costs, individual cost components, and forms and levels of training; factors for the base standard costs based on objective characteristics of institutions; factors for budgetary constraints on individual cost components and forms and levels of training. 
The analytical parameters include the intermediate values obtained in the process of calculation and required for the overall analysis of calculation results and its individual components.

The output parameters for calculation include the indicators of financial support for a government assignment by institutions, public services, and cost components, and model verification indicators.

The system of actions that provide for the calculation of financial support for a government assignment is set by the institutional regulatory framework and includes the following key operation blocks:

- Aggregation of input data by specialty cost groups;

- Calculation of standard costs for individual cost components;

- Calculation of integrated factors for standard cost components (for analytical purposes);

- Calculation of the financial support for the government assignment;

- Aggregation of the financial support for the government assignment.

The system of actions that provide for model verification is based on postulating model stability, is determined by experts and ensures control over compliance with absolute values and relative changes of input, analysis and output parameters. The base standard cost, system of factors (indirectly through standard costs with due regard for factors), and the technical implementation of calculation are subject to verification.

\section{Conclusions}

The solutions described make it possible to build an upgradable integrated information system for automation and information support of funding for educational institutions that integrates both previously developed and newly developed subsystems.

The most "unstable" elements are implemented using architecture and technical solutions that make it possible to rapidly adapt the algorithmic and model base to a wide range of changes in the regulatory and methodological documents governing the main stages of funding.

The application created in the complex information systems of the developed model calculation and adaptable set of software tools allowed (compared to the singlepurpose information systems) to reduce the complexity and time required for the calculations of the same scenarios for the funding agencies.

Further areas of research are as follows:

- Integrating the developed package into the federal information environment for preparing the electronic budget;

- Disseminating the developed solutions and experience obtained in the course of their implementation to other federal executive bodies that have institutions providing public services in the area of professional education in the structure of their subordinate network. 
Alashkevich, M.; Bobryakov, A.; Klimenko, A. \& Stefantsov, A.: Automation and I...

\section{Acknowledgments}

The authors express their acknowledgments to:

- Employees of the Department of Finance, Organization of Budgeting, Methodology and Economy of Science and Education of the Russian Ministry of Education and Science for their methodological support in formulating and solving the problems of automation and information support for funding subordinate educational institutions;

- Employees of the Center of Branch Information-Analytical Systems of the National Research University "Moscow Power Engineering Institute" for their work on designing and developing individual information systems and system support of the integrated package;

- Employees of Business Information Systems LLC for development of individual information systems included in the integrated package.

\section{References}

Borovskaya, M.; Yastrebova, O.; Tsvetkova, A. (2012) A New Mechanism for Financing Institutions of Higher Education: The First Results, Higher Education in Russia, No. 5, (May 2014) pp. 3-14, ISSN 0869-3617 (in Russian)

Davies, J.; Gibbons, J.; Welch, J.; et al. (2014). Model-driven engineering of information systems: 10 years and 1000 versions, Science of Computer Programming, Vol. 89, (September 2014) pp. 88-104, ISSN: 0167-6423

Inmon, W.; Linstedt, D. (2014). Data Architecture: A Primer for the Data Scientist, Morgan Kaufmann, ISBN 978-0-12-802044-9, Burlington

Klimenko, A.; Volodin, A.; Bobryakov; A.; et al. (2013) Approaches to Organizing and Building an Information System for Monitoring the Financial and Economic Activities of Institutions Subordinate to the Russian Ministry of Education and Science, Bulletin of the Moscow Power Engineering Institute, No. 1, (March 2013) pp. 114-119, ISSN 1993-6982 (in Russian)

Sato-Ilic, M. (2014). Fuzzy Systems (FUZZ-IEEE), IEEE International Conference, Universal fuzzy clustering model, pp. 2071-2078, ISBN: 978-1-4799-2073-0, Beijing, July 2014, IEEE

Shilovskaya, L.; Bobryakov, A.; Stefantsov, A. (2013) The Concept of Developing an Information System for Calculating Financial Support for a Government Assignment for Provision of Public Services in the Area of Professional Education, Bulletin of the Moscow Power Engineering Institute, No. 4, (October 2013), pp. 235-241, ISSN 19936982 (in Russian) 